\title{
Processing of Niobium-Lined M240 Machine Gun Barrels
}

by William S de Rosset and David Gray

ARL-TR-7144

November 2014

Approved for public release; distribution is unlimited. 


\section{NOTICES}

\section{Disclaimers}

The findings in this report are not to be construed as an official Department of the Army position unless so designated by other authorized documents.

Citation of manufacturer's or trade names does not constitute an official endorsement or approval of the use thereof.

Destroy this report when it is no longer needed. Do not return it to the originator. 


\title{
Army Research Laboratory
}

Aberdeen Proving Ground, MD 21005-5069

\section{Processing of Niobium-Lined M240 Machine Gun Barrels}

\author{
William S de Rosset \\ Oak Ridge Institute for Science and Education
}

David Gray

Weapons and Materials Research Directorate, ARL 


\section{REPORT DOCUMENTATION PAGE}

Form Approved OMB No. 0704-0188

Public reporting burden for this collection of information is estimated to average 1 hour per response, including the time for reviewing instructions, searching existing data sources, gathering and maintaining the data needed, and completing and reviewing the collection information. Send comments regarding this burden estimate or any other aspect of this collection of information, including suggestions for reducing the burden, to Department of Defense, Washington Headquarters Services, Directorate for Information Operations and Reports (0704-0188), 1215 Jefferson Davis Highway, Suite 1204, Arlington, VA 22202-4302. Respondents should be aware that notwithstanding any other provision of law, no person shall be subject to any penalty for failing to comply with a collection of information if it does not display a currently valid OMB control number.

PLEASE DO NOT RETURN YOUR FORM TO THE ABOVE ADDRESS

\begin{tabular}{|l|l|l|}
\hline 1. REPORT DATE $(D D-M M-Y Y Y Y)$ & 2. REPORT TYPE & 3. DATES COVERED (FrOm - To)
\end{tabular}

November 2014

Final

January 2013-August 2014

4. TITLE AND SUBTITLE

5a. CONTRACT NUMBER

Processing of Niobium-Lined M240 Machine Gun Barrels

5b. GRANT NUMBER

5c. PROGRAM ELEMENT NUMBER

6. AUTHOR(S)

William S de Rosset and David Gray

5d. PROJECT NUMBER

AH84

5e. TASK NUMBER

5f. WORK UNIT NUMBER

8. PERFORMING ORGANIZATION

REPORT NUMBER

US Army Research Laboratory

ATTN: RDRL-WMM-F

Aberdeen Proving Ground, MD 21005-5069

9. SPONSORING/MONITORING AGENCY NAME(S) AND ADDRESS(ES)

ARL-TR-7144

10. SPONSOR/MONITOR'S ACRONYM(S)

11. SPONSOR/MONITOR'S REPORT

NUMBER(S)

12. DISTRIBUTION/AVAILABILITY STATEMENT

Approved for public release; distribution unlimited.

13. SUPPLEMENTARY NOTES

14. ABSTRACT

Niobium liners have been emplaced in M240 machine gun barrel blanks with the Gun Liner Emplacement with an Elastomeric Material process. The barrel blanks were hammer forged and machined to produce finished barrels. These barrels were test fired at the US Army Research Laboratory at a low rate. No liner movement or extension was observed during the tests, although there was a preexisting extension in the first barrel.

15. SUBJECT TERMS

gun liners, bore measurements, refractory metals, machine guns, firing tests

\section{SECURITY CLASSIFICATION OF:}

a. REPORT

Unclassified

b. ABSTRACT
Unclassified

Unclassified
17. LIMITATION
OF ABSTRACT

c. THIS PAGE

UU
18. NUMBER

OF PAGES

28 19a. NAME OF RESPONSIBLE PERSON

William S de Rosset

19b. TELEPHONE NUMBER (Include area code) 410-306-0816 


\section{Contents}

List of Figures $\quad$ iv

List of Tables $\quad$ iv

$\begin{array}{ll}\text { Acknowledgments } & \text { v }\end{array}$

$\begin{array}{ll}\text { 1. Introduction } & 1\end{array}$

2. Liner Dimensions $\quad 2$

3. Experimental Approach $\quad 4$

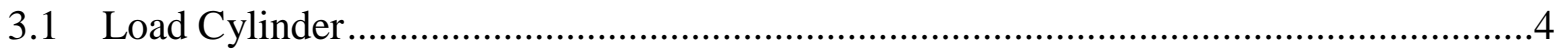

3.2 Equipment and Processing Parameters for Tube 1 ..................................................5

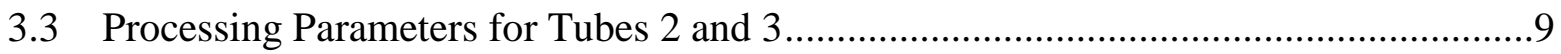

4. Firing Test Results $\quad 10$

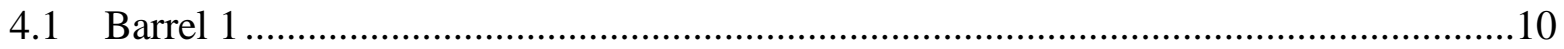

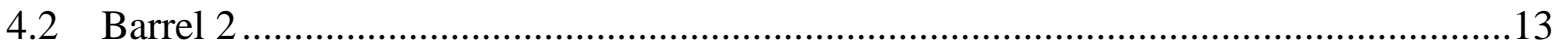

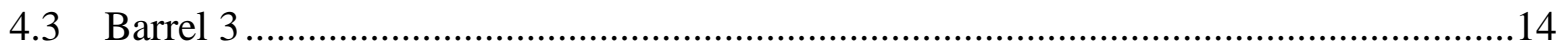

5. Discussion $\quad 15$

6. Conclusions 16

$\begin{array}{ll}\text { 7. Summary } & 17\end{array}$

$\begin{array}{llr}\text { 8. } & \text { References and Notes } & 18\end{array}$

$\begin{array}{ll}\text { Distribution List } & 20\end{array}$ 


\section{List of Figures}

Fig. 1 Schematic of the GLEEM process........................................................................

Fig. 2 Gun tube and niobium-liner hardware .................................................................

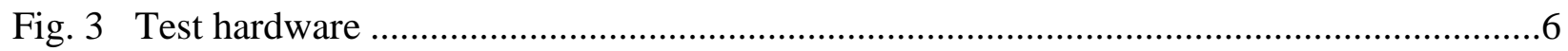

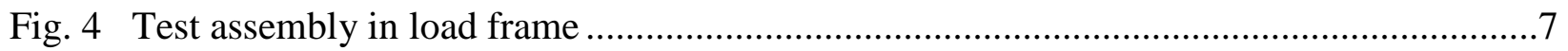

Fig. 5 Finished niobium-lined M240 machine gun barrel with flash suppressor attached ..........11

Fig. 6 End of barrel 1 showing small amount of liner protrusion..........................................12

Fig. 7 Bore diameter measurements at the land and groove locations for barrel 1 ....................13

Fig. 8 Bore diameter measurements at the land and groove locations for barrel 3...................14

\section{List of Tables}

Table 1 Processing parameters for tube 1 ......................................................................8

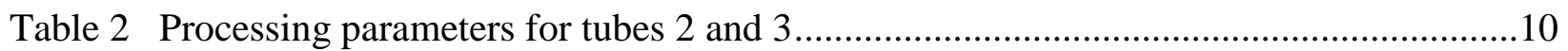

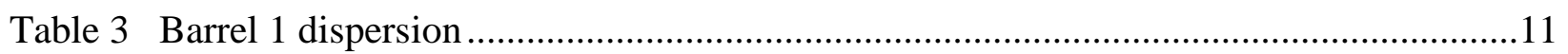

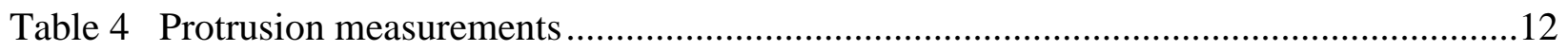

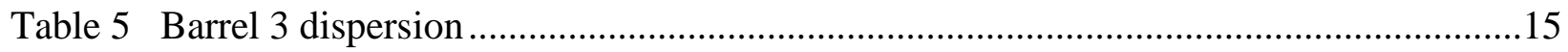




\section{Acknowledgments}

The authors acknowledge the contributions of Robert Keppinger for making the bore measurements, Tom Puckett and his staff for conducting the firing tests, Hoang Nguyen for the Gun Liner Emplacement with an Elastomeric Material (GLEEM) processing of the tubes, Bob Sewell (FN Manufacturing) for coordinating the final machining of the tubes, and Robert Kaste for helping in the design of the containment device used in the GLEEM processing. Most importantly, we acknowledge the original idea of hammer forging barrels with liners conceived by Jonathan Montgomery. Without the effort of these people, this work would not have been possible. 
INTENTIONALLY LEFT BLANK. 


\section{Introduction}

For the past several years, the US Army Research Laboratory (ARL) and others have been engaged in applying refractory metal liners to gun tubes. The primary goal of this work is to extend the useful service life of Army gun tubes. The early research centered on explosive bonding of these liners, ${ }^{1-8}$ and later work ${ }^{9-12}$ explored a new process called Gun Liner Emplacement with an Elastomeric Material (GLEEM). This is a process by which the liner is pressed against the gun tube wall with a pressurized elastomeric material, thus forming a frictional bond between the gun tube and the liner. The most recent efforts culminated with the firing of a truncated M242 gun barrel with a Stellite 25 liner. ${ }^{13}$

The GLEEM process must proceed in several passes. The friction between the elastomer and the gun tube wall prevents a uniform distribution of pressure. Consequently, the tube must be filled with a partial length of the elastomer for each pass. Figure 1 shows a schematic of this process. A load frame applies pressure to the load cylinder, which in turn pressurizes the elastomer. The number of passes depends on the length of the tube. The schematic shows a barrel that has a chamber already machined in it. The inversion procedure (shown in pass 4 ) is necessary to complete the process on the muzzle end of the tube.

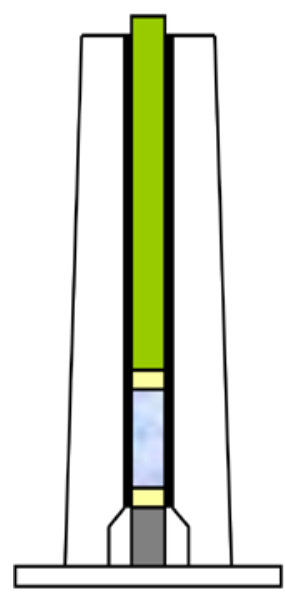

Pass 1

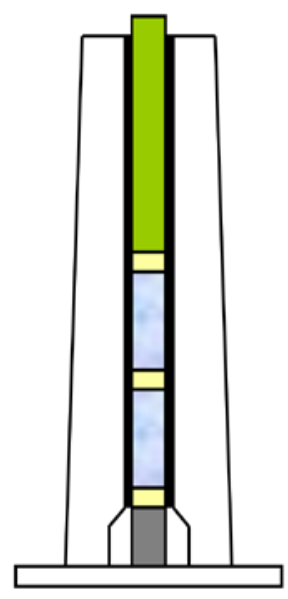

Pass 2

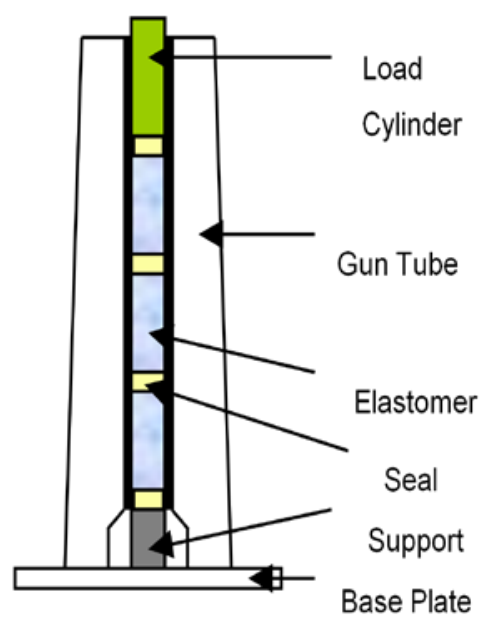

Pass 3

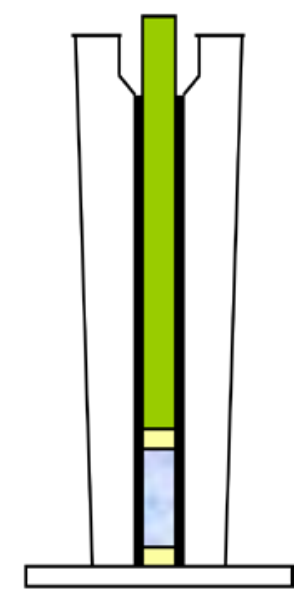

Pass 4

Fig. 1 Schematic of the GLEEM process

Several lessons were learned during the processing of the truncated M242 tube. First, the alignment of the test fixture and load cylinder with the load frame is critical. Even with a great deal of care, the load cylinder is not perfectly aligned with the load frame, and buckling of the load cylinder was experienced on several occasions. The motion of the load cylinder must be monitored and the test stopped if buckling begins. 
Second, the length of the elastomer must be kept as short as practical. An elastomer length was chosen for the M242 barrel that appeared to be reasonable, based on the laboratory tests. However, the length chosen resulted in low bond strength, likely the cause of the liner extension observed during the test firings. It was shown that the extension was made up of both liner stretching and liner displacement.

Third, the bond strength achieved by the GLEEM process was sufficient to keep the liner in place while the lands and grooves were machined in it. It was also demonstrated that the Stellite 25 liner could be rifled by conventional means.

After the work with the M242 medium-caliber cannon tube was completed, attention was focused on the M240 machine gun tube. Previous work with the M249 machine gun had shown the possibility that a refractory metal liner could do away with firing restrictions on the tube and relieve the machine gunner of carrying a second gun tube. ${ }^{14,15}$ The general approach to be taken was first to use the GLEEM process to emplace a liner in a barrel blank and then have the barrel blank hammer forged by FN Manufacturing (FN), Columbia, SC. Niobium was chosen as the refractory metal based on its cost and machineability. However, the possibility of using other refractory metals later was left open. Section 2 gives the considerations for choice of liner thickness. Section 3 details the experimental apparatus and procedures used for the first and subsequent processing attempts. Section 4 provides the results of firing the gun tubes, and Section 5 gives a short discussion of the results. Section 6 summarizes the work.

\section{Liner Dimensions}

An important decision to be made was the liner thickness. The decision was based on several considerations. A general range of thicknesses can be obtained by scaling liner thicknesses from other gun tubes. For instance, the Stellite 21 liner thickness used in the 0.50-caliber M2 machine gun is 0.1 inch (2.54 mm). A simple geometric scaling for the 7.62-mm M240 machine gun barrel would result in a liner thickness of 0.060 inch $(1.5 \mathrm{~mm})$. The liner thickness used successfully in the M242 Bushmaster cannon was approximately 0.065 inch (1.65 mm). Similar geometric scaling gives a suggested 0.019 inch $(0.49 \mathrm{~mm})$ for the niobium liner thickness.

One advantage of a refractory metal liner is that it provides thermal protection to the underlying steel gun tube. In particular, if the liner is thick enough, the temperature of the steel can be kept below its phase transformation. Witherell ${ }^{16}$ has calculated the minimum liner thickness to prevent a phase transformation in a medium caliber gun tube. Using FDHEAT, an in-house Benét Laboratories heat transfer code, he showed that the minimum liner thickness was a function of position along the barrel, the type of ammunition fired, and the liner material. Similar effects would likely be seen for smaller-caliber gun tubes. For the medium-caliber gun tube, 
Witherell calculated the required liner thicknesses to range from 0.005 to 0.010 inch $(0.127$ to $2.54 \mathrm{~mm}$ ). The final niobium liner thickness will be between 0.02 and 0.060 inch, so this minimum liner thickness requirement does not appear to be a driver for the final choice.

Cracks will inevitably occur in any liner material. However, if the liner is thick enough, the cracks will be arrested in the liner material and never get to the steel. This suggests using a liner thickness that is the upper portion of the range determined from geometric scaling. Even if the cracks get to the steel barrel, if the liner is thick enough, there will be very little damage done to the steel. For instance, cracks were observed in the Stellite 21 liner in the M2 machine gun (March 2013 conversation with JS Montgomery; unreferenced). Even though the cracks went completely through the liner, the underlying steel was not affected. This is not always the case, however, for chromium coatings. These coatings are so thin ( $\sim 0.01$ inch) that cracks in the coating observed, for instance in 120 -mm gun tubes, propagate into the steel.

Cost is an important consideration for the liner thickness. Refractory metals are not inexpensive, and the increase in service life provided by liners must be high enough to justify the higher upfront costs. If cost is an issue, then it might be possible to line only a portion of the gun tube, as is done with the M2 machine gun.

Finally, the liner must be capable of withstanding rough handling during the production process. Therefore, a liner that is in the upper range of thicknesses determined from geometric scaling would be preferable.

Most of these considerations argue for as thick a liner as possible. Therefore, the liner thickness was chosen to be 0.060 inch $(1.52 \mathrm{~mm})$. The mandrel used in the hammer forging process fits into the center hole in the steel barrel blank that is 0.315 inch $(8.00 \mathrm{~mm})$ in diameter. Therefore, this would be the minimum diameter of the niobium liner obtained after the composite gun tube is processed with GLEEM. The decision was made to start with a liner inner diameter of 0.312 inch $(7.92 \mathrm{~mm})$ and allow a clearance of 0.001 inch $(0.025 \mathrm{~mm})$ between the liner and gun tube. Thus, the GLEEM process would have to produce at least a 0.001 inch $(0.025 \mathrm{~mm})$ expansion of the steel cylinder to allow the mandrel to fit inside the liner.

The other dimensions were determined as follows. The outer diameter of the niobium liner was found by adding twice the wall thickness to the inner diameter. This calculation gave 0.432 inch $(10.97 \mathrm{~mm})$ as the final diameter. The center hole in each of the steel barrel blanks obtained from FN Manufacturing was reamed out to 0.434 inch $(11.02 \mathrm{~mm})$ in diameter. The barrel blanks were 22 inches $(558.8 \mathrm{~mm})$ long, so this was the length chosen for the niobium liners. A picture of the barrel blank and niobium liner is shown in Fig. 2. 


\section{Barrel Blank}

\section{Niobium Liner}

Fig. 2 Gun tube and niobium-liner hardware

\section{Experimental Approach}

\subsection{Load Cylinder}

The load cylinder outer diameter was taken to be 0.308 inch $(7.82 \mathrm{~mm})$, giving enough clearance between it and the niobium liner to ensure easy insertion. The material chosen initially for the load cylinder was S-7 tool steel. However, a problem with rod buckling was experienced on one of the early passes, so the material was changed to Vascomax 300.17

The load area on the load cylinder is quite small. If the yield point $Y_{1}$ of the Vascomax 300 is 275100 psi, ${ }^{17}$ then the maximum load $L_{m}$ that can be sustained without yielding is given by

$$
L_{m}=\pi r^{2} Y_{1}
$$

where $r$ is the radius of the load cylinder ( 0.154 inch). This gives $L_{m}=20500 \mathrm{lb}$. As an approximation, we assume that the load applied to the load cylinder is transmitted hydrostatically to the liner. That is,

$$
P=L / A \text {, }
$$

where $P$ is the hydrostatic pressure, $L$ is the load applied to the load cylinder, and $A$ is the crosssectional area of the load cylinder.

In this case, the pressure $P_{p}$ needed to plastically deform the entire cylinder (assuming elasticperfectly plastic behavior) is given by

$$
P_{p}=Y_{2} \ln (b / a)
$$


where $a$ and $b$ are the inner and outer radii of the gun tube, respectively. $Y_{2}$ is the yield point of the steel gun tube. The value of $b$ was measured to be 0.6675 inch (16.95 mm). The choice for $a$ was not as clear. It could either be the inner radius of the steel gun tube, the inner radius of the original liner, or the radius of the liner after it has expanded to contact the steel gun tube. Pressures were calculated for each of these values.

The hardness of the steel gun tube was measured to be HRC 33.1. This can be converted to tensile strength with a standard chart. The tensile strength of the gun steel was found to be $150 \mathrm{ksi}$. The yield point $Y_{2}$ is then estimated to be $140 \mathrm{ksi}$ (2013 conversation with JS Montgomery; unreferenced). The 3 calculated values of $P_{p}$ are then 203.5202.6, and $157.3 \mathrm{ksi}$. The cross-sectional area of the load cylinder can then be used to calculate the following necessary loads: 15.2, 15.1, and 11.7 kip. These values are all below the load that would yield the load cylinder (20.5 kip). In the actual passes, a maximum load of 16 kip was first chosen to maximize the plastic work in the steel cylinder. This was later reduced to 14 kip.

The other possibility of load cylinder failure is buckling. The load cylinder insider the liner is reasonably well supported, so the unsupported length is that left outside the liner. This length will change as the GLEEM process is carried out, since the elastomer compresses a substantial amount. In an ideal situation, the buckling load $L_{b}$ is given by

$$
L_{b}=\pi^{2} E I /(K \lambda)^{2} \text {, }
$$

where $E$ is the elastic modulus of the load cylinder, $I$ is its area moment of inertia, $K$ is the effective length parameter, and $\lambda$ is the unsupported load cylinder length. For a load of 16 kip, the maximum unsupported length would be 3 inches, assuming $K=1$. Equation 4 generally overestimates the value of $\lambda$, since ideal conditions do not exist in the laboratory. The approach used was to select a combination of load cylinder and elastomer lengths such that the unsupported length was as small as possible at the maximum load. The amount of compression obtained from each length of elastomer was not known before the pass was made, so the first barrel blank was processed on a trial-and-error basis.

\subsection{Equipment and Processing Parameters for Tube 1}

Figure 3 shows some of the separate parts that were used in the processing. These include the steel surround, a lower containment cup, the length of elastomer (made up of several short pieces), and the load cylinder. The niobium liner is inside the barrel blank. The lower containment cup supported the bottom end of the barrel blank. It was designed so that it would hold both ends of the barrel blank. 


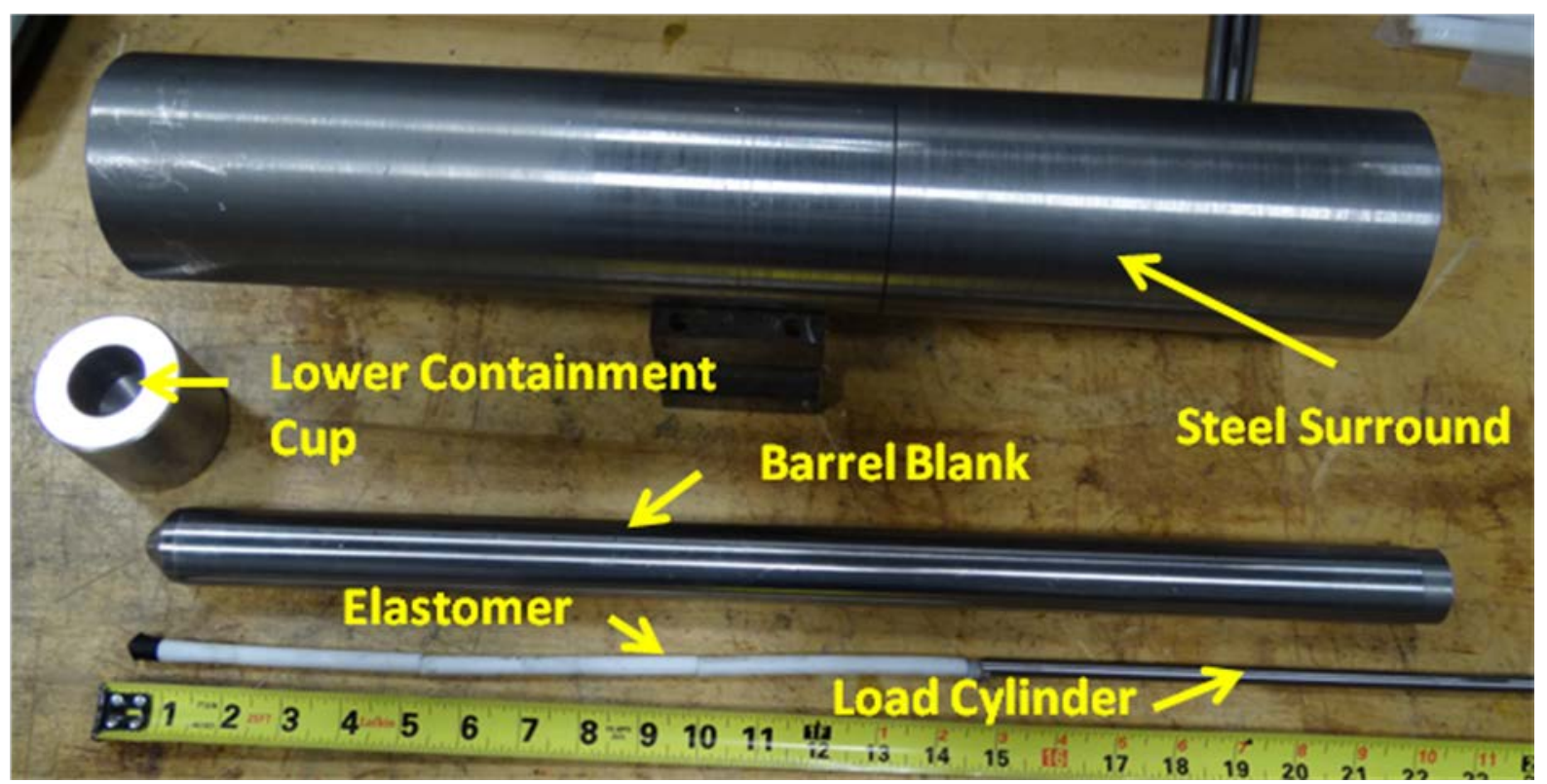

Fig. 3 Test hardware

Figure 4 shows the test assembly in the load frame. The steel surround, containing the barrel blank, niobium liner, and load cylinder, is held in place by 4 tie rods that connect the gymbal base to the upper containment plate. (The gymbal base was used previously to process the M242 tubes. By adjusting the screws in the base, the barrel blank and steel surround could be aligned with the axis of the load machine). The tie rods prevented the nylon seal at the bottom end of the barrel blank from escaping. The upper containment cup was attached to the load frame and helped keep the load cylinder in place.

The load machine was an Instron 5000R, capable of exerting a load of 50,000 lb. At the beginning of the processing of tube 1 , the displacement of the load cylinder for a given length of elastomer at a given load was not known. Consequently, the load machine was run in displacement control. That is, after a given displacement was reached, the load machine would maintain that displacement at that point. To get to the final load, the load was increased manually, making sure the upper containment cup did not contact the top containment plate. 


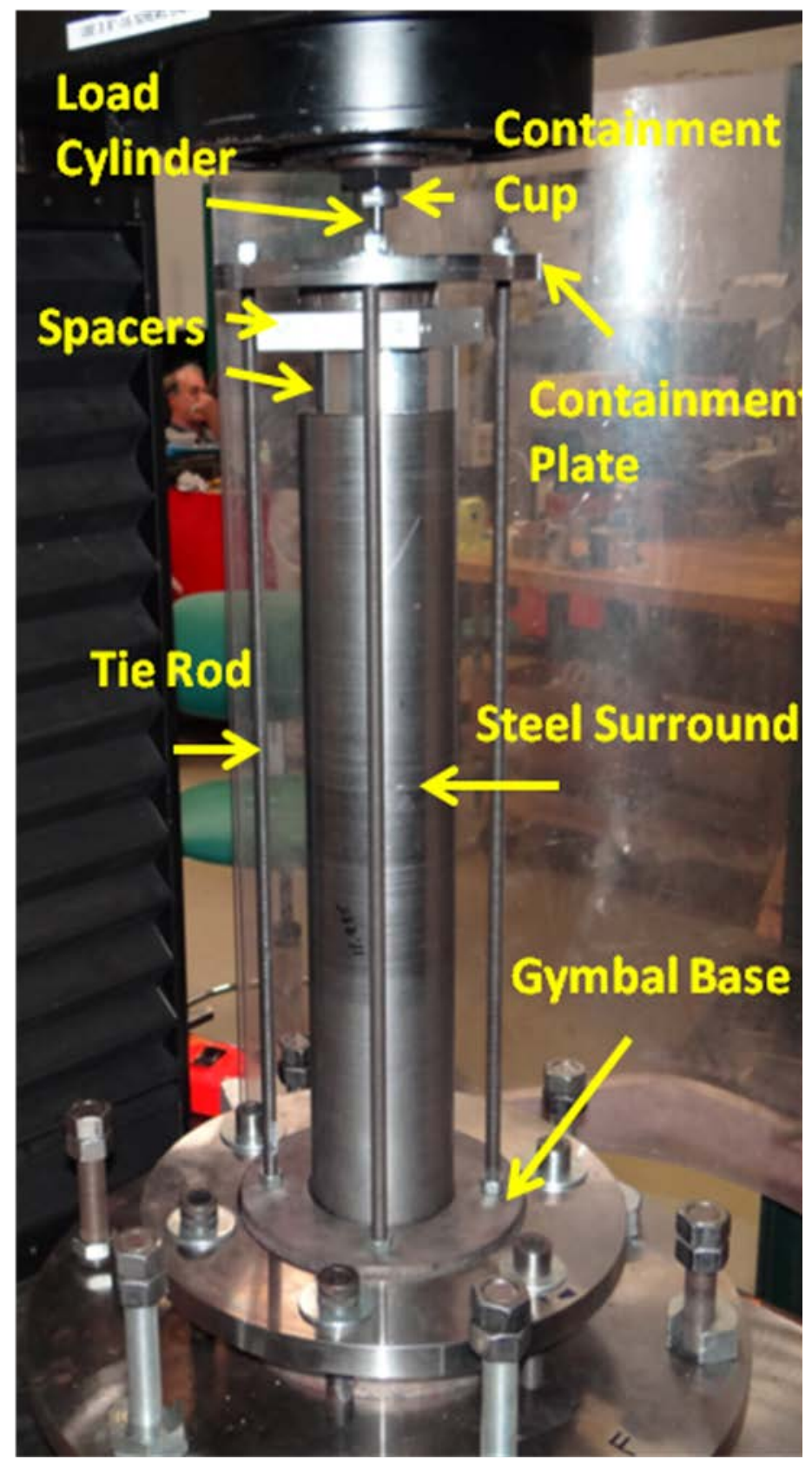

Fig. 4 Test assembly in load frame

After some data were collected and the displacement versus elastomer length was determined, the load machine was run under load control. Under displacement control, the load decreased after reaching a given displacement. Under load control the displacement of the load cylinder increased at constant load. Ramp rates started out at $0.05 \mathrm{inch} / \mathrm{s}$ (under displacement control) and ended up at 1,000 lb/min (under load control). 
The first processing step used one-half inch of nylon as the seal at the muzzle end of the tube, 2 inches of elastomer, one-quarter nylon seal, and 21.5 inches of load cylinder. The load cylinder was made up of an 18-inch rod and a 3.5-inch rod. After the first pass was completed, it was found that the one-half inch nylon seal was permanently deformed to 0.4375 inch. The same seal was used for the remainder of the passes until the gun tube was flipped. In the flipped configuration, a new 0.5-inch nylon seal was used. In all cases, the upper nylon seal was 0.25 inch long.

Table 1 is a summary of the processing parameters for tube 1 . Column 1 gives the pass number, column 2 is the length of elastomer used in the pass, and column 3 is the length of load cylinder used. The elastomer length was made up of short lengths of Teflon, and in several cases the load cylinder was in 2 pieces. Column 4 is the maximum load achieved in the pass, column 5 is the load cylinder displacement, and column 6 offers specific comments about the pass. Notes referred to in column 6 can be found just after the table. Displacement control was used for passes 1-9, and load control was used for the last 4 passes.

Table 1 Processing parameters for tube 1

\begin{tabular}{|c|c|c|c|c|c|}
\hline $\begin{array}{l}\text { Pass } \\
\text { No. }\end{array}$ & $\begin{array}{c}\text { Elastomer } \\
\text { Length } \\
\text { (inches) }\end{array}$ & $\begin{array}{l}\text { Load } \\
\text { Cylinder } \\
\text { Length } \\
\text { (inches) }\end{array}$ & $\begin{array}{c}\text { Maximum } \\
\text { Load } \\
\text { (kip) }\end{array}$ & $\begin{array}{c}\text { Load } \\
\text { Cylinder } \\
\text { Displacement } \\
\text { (inches) }\end{array}$ & Comments \\
\hline 1 & 2.0 & 21.5 & 16.4 & 1.1 & Note 1 \\
\hline 2 & 3.75 & 21.5 & 14.0 & 1.35 & Rod bent \\
\hline 3 & 3.75 & 20.0 & 16.0 & 1.39 & Note 1 \\
\hline 4 & 5.75 & 17 & $\ldots$ & $\ldots$ & Note 2 \\
\hline 5 & 5.75 & 18 & 16.0 & 1.53 & Note 1 \\
\hline 6 & 8.0 & 16 & 7.3 & 1.70 & Note 2 \\
\hline 7 & 8.5 & 16 & 16.0 & 2.03 & Note 1 \\
\hline 8 & 10.5 & 13.5 & 8.2 & 2.1 & Note 2 \\
\hline 9 & 11.5 & 13.5 & 16.0 & 2.25 & $\begin{array}{l}\text { Note 1; } \\
\text { load } \\
\text { cylinder } \\
\text { stuck }\end{array}$ \\
\hline 10 & 14 & 11.5 & 14.0 & 2.51 & $\begin{array}{c}\text { Pass } \\
\text { interrupted } \\
\text { by power } \\
\text { failure }\end{array}$ \\
\hline 11 & 16.5 & 9.0 & 14.0 & 2.57 & $\ldots$ \\
\hline 12 & 18.75 & 6.5 & 14.0 & 2.83 & $\ldots$ \\
\hline 13 & 6.0 & 19.0 & 14.0 & 2.09 & $\begin{array}{l}\text { Gun tube } \\
\text { flipped }\end{array}$ \\
\hline
\end{tabular}

Note 1: Load fell to a value between 14 and 15 kip during a 10-min hold

Note 2: Test stopped before target load reached; incorrect estimate of load cylinder displacement 
Unlike the GLEEM processing of the M242 tube, the load cylinders used to process the M240 tube did not have any means to attach them to a pull-out device. In many instances, the top nylon seal extruded past the load cylinder, causing it to become stuck in the tube. In some instances, an arbor press was used to extract the load cylinder. In another instance, a piece of metal was welded to the exposed portion of the load cylinder, allowing the load cylinder to be gripped and extracted from the tube.

As previously mentioned, the behavior of the elastomer under a given load was not known at first. With increasing numbers of passes, displacement-versus-elastomer-length data points were collected. It was observed that when a fresh piece of elastomer was used in a test, it was permanently shortened. (The diameter expanded to make up for the decrease in length.) For instance, two 3-inch pieces of elastomer were used for pass 13. The resulting lengths were 2.86 and 2.74 inches. (The shorter 3-inch piece of elastomer was in contact with the load cylinder.) The displacement of the load cylinder thus depended on the ratio of "old" and "new" elastomer. After the first pass, the old elastomer was used as much as possible. The result was a reasonably linear relation between the length of elastomer and the load cylinder displacement.

\subsection{Processing Parameters for Tubes 2 and 3}

From the experience gained in processing tube 1, a set of processing parameters was standardized and used on the next 2 tubes. These parameters are shown in Table 2. For pass no. 9, the barrel blank was flipped upside down. For each pass, the load frame was run under load control. The load was ramped at a rate of $1,000 \mathrm{lb} / \mathrm{min}$ until a load of $14,000 \mathrm{lb}$ was reached. The load was held for $10 \mathrm{~min}$, during which time the pusher rod displacement continued to grow. The load was then released and preparations for the next pass were made. No problems were encountered in extracting the load cylinder from the barrel blank. At maximum load, the unsupported load cylinder length was generally an inch or less; no bending of the pusher rod was observed. 
Table 2 Processing parameters

for tubes 2 and 3

\begin{tabular}{|c|c|c|}
\hline $\begin{array}{c}\text { Pass } \\
\text { No. }\end{array}$ & $\begin{array}{c}\text { Elastomer } \\
\text { Length } \\
\text { (inches) }\end{array}$ & $\begin{array}{c}\text { Load } \\
\text { Cylinder } \\
\text { Length } \\
\text { (inches) }\end{array}$ \\
\hline 1 & 3 & 21 \\
\hline 2 & 5 & 19 \\
\hline 3 & 7.5 & 17 \\
\hline 4 & 9.5 & 15 \\
\hline 5 & 12 & 13 \\
\hline 6 & 14 & 11 \\
\hline 7 & 16.25 & 9 \\
\hline 8 & 18.5 & 7 \\
\hline 9 & 6 & 19 \\
\hline
\end{tabular}

One refinement was made to the third niobium liner. A thin layer of tungsten-carbide particles was cold sprayed onto the outside of the liner with a Cold Gas Technology Kinetic 4000 system. The source of the tungsten-carbide particles was ATI/Firth Sterling, Huntsville, AL. The surface of the niobium was preconditioned by spraying it with silicon-carbide particles. The coating thickness was approximately 0.0005 inch thick. The barrel blank was enlarged slightly with a reamer to accommodate the increase in liner diameter. This process was done in an attempt to increase the bond strength after the GLEEM process and hammer forging of the barrel.

\section{Firing Test Results}

\subsection{Barrel 1}

The first barrel was sent to FN Manufacturing (FN) in early May 2013. It was returned to ARL in February 2014. The delay was due to the schedule used for the production run of the standard M240 barrels. During the processing of the first barrel, the mandrel broke before the hammer forging process was completed. FN was able to salvage enough barrel length to make a shorter version of the standard-length M240 machine gun barrel. This is what was used in the firing tests. A picture of the finished barrel is shown in Fig. 5. 


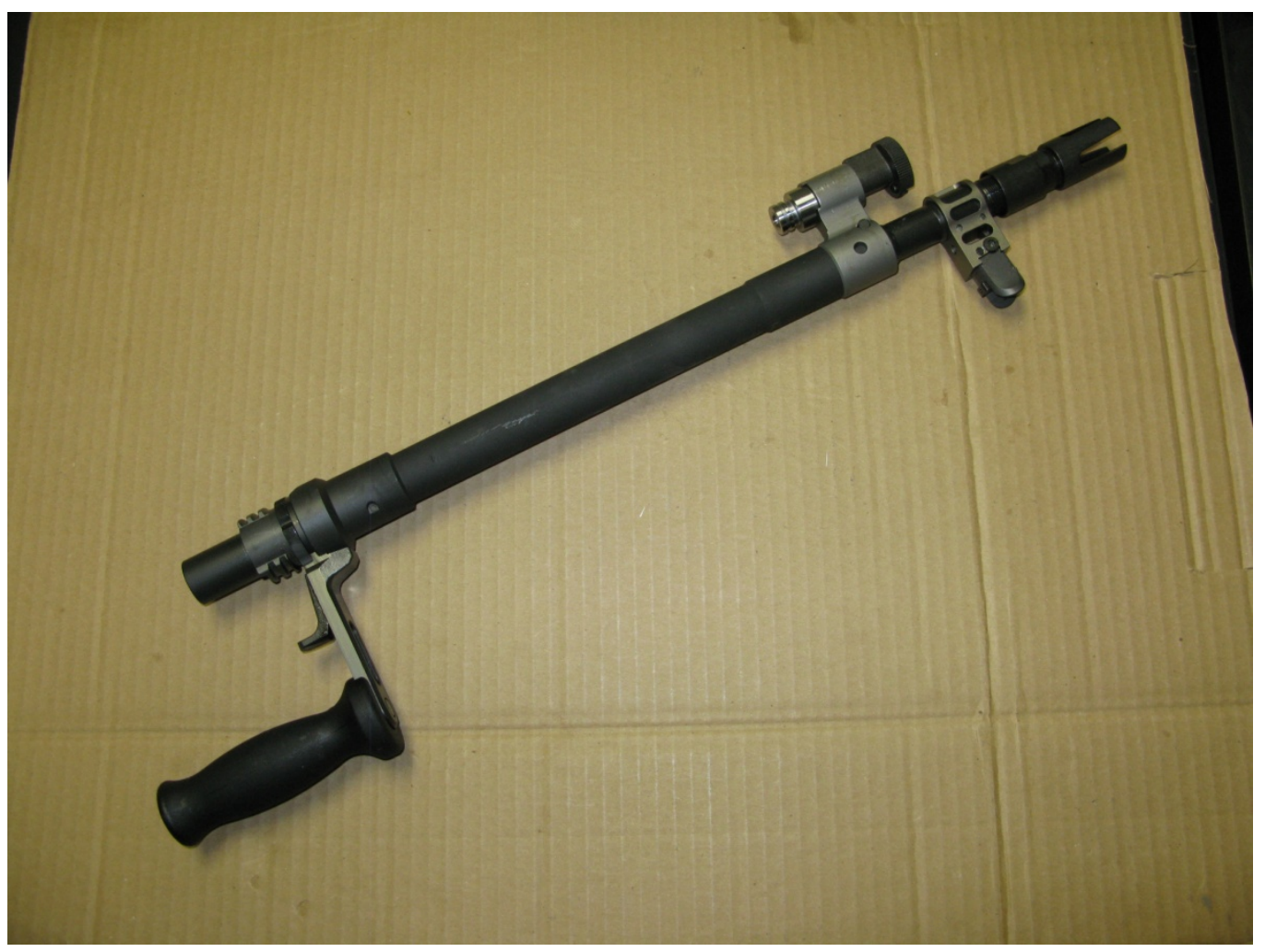

Fig. 5 Finished niobium-lined M240 machine gun barrel with flash suppressor attached

Firing tests were conducted in the Aerodynamics Experimental Test Facility. The test director noted that there were gouges in the chamber area of the gun tube. This would not prevent the tests from going forward, since they were in single-shot mode. However, rapid fire tests might have resulted in jamming of the cartridge.

The test plan called for 10 warmer shots in single-shot mode, followed by 3 groups of 30 shots each, also in single-shot mode. Bullet impact location was recorded, and muzzle velocity was measured. The dispersion for each 30-round group is given in Table 3.

Table 3 Barrel 1 dispersion

\begin{tabular}{|c|c|c|}
\hline \multirow{2}{*}{ Group No. } & \multicolumn{2}{|c|}{$\begin{array}{c}\text { Dispersion } \\
\text { (mils) }\end{array}$} \\
\cline { 2 - 3 } & $\mathbf{X}$ & $\mathbf{Y}$ \\
\hline 1 & 0.454 & 0.384 \\
\hline 2 & 0.395 & 0.495 \\
\hline 3 & 0.428 & 0.417 \\
\hline
\end{tabular}

FN fired a proof slug through the barrel before it was shipped to ARL. This may have been the cause of a slight protrusion of the liner that was observed before the ARL firing tests began. The first 10 shots did not result in any apparent liner movement. Unfortunately, a baseline measurement of the liner extension was not taken before the tests began. The test director 
measured an extension of 0.0035 inch of the niobium liner past the muzzle end of the gun tube after the first 40 shots. The next 60 shots resulted in no measurable liner extension. Since a baseline was not measured before the tests began, it is not clear if the liner moved or was stretched during the first 40 shots. A side view of the end of the barrel is shown in Fig. 6 .

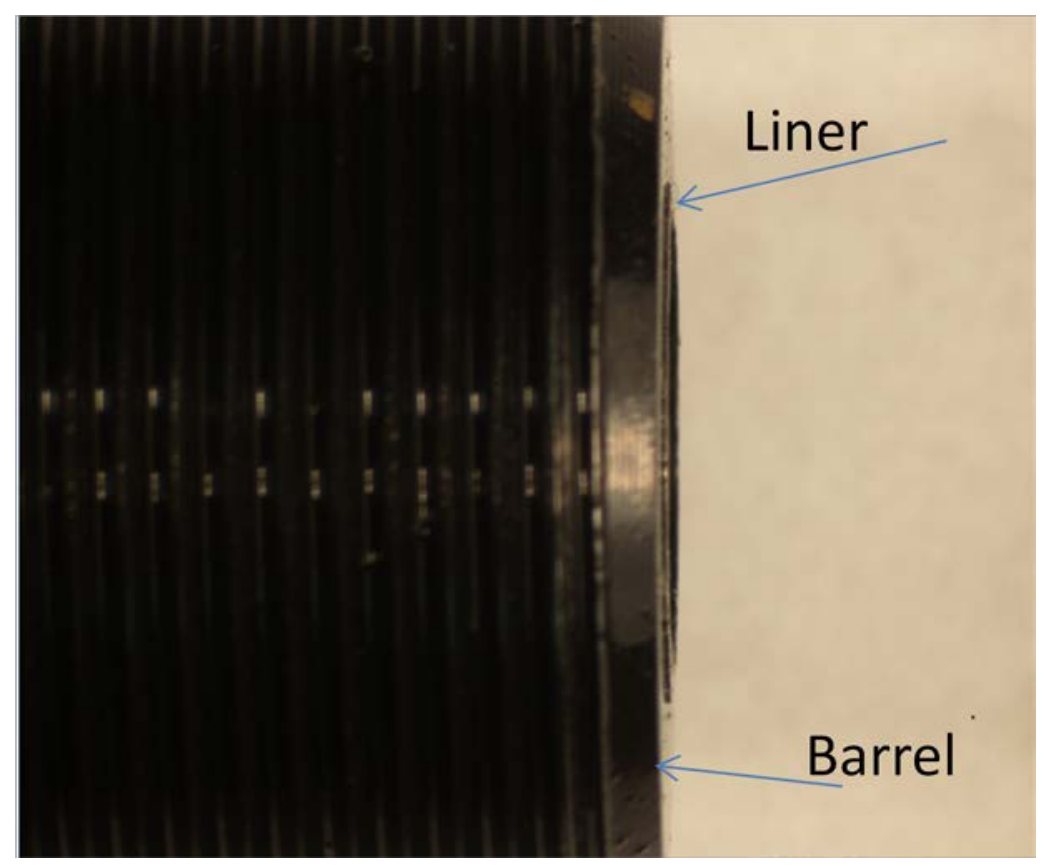

Fig. 6 End of barrel 1 showing small amount of liner protrusion

After the tests were completed, 4 measurements of the liner protrusion were made at $90^{\circ}$ intervals around the circumference of the liner. These measurements are shown in Table 4. The first measurement shown was taken at the "noon" position; the rest followed clockwise looking down the barrel from the rear.

Table 4 Protrusion measurements

\begin{tabular}{|c|c|c|}
\hline \multirow{2}{*}{ Measurement No. } & \multicolumn{2}{|c|}{ Protrusion } \\
\cline { 2 - 3 } & inches & mm \\
\hline 1 & 0.0015 & 0.038 \\
\hline 2 & 0.0030 & 0.076 \\
\hline 3 & 0.0040 & 0.102 \\
\hline 4 & 0.0032 & 0.081 \\
\hline
\end{tabular}

A Bore Erosion and Measurement Instrumentation System ${ }^{18}$ (BEMIS) was used to measure the bore diameter at both the land and groove locations. These measurements are shown in Fig. 7. 
The protrusion of the liner presented an opportunity to measure its thickness. The outer diameter of the liner was measured to be $10.29 \mathrm{~mm}$ (0.4055 inch). Taking the bore diameter at the groove location as $7.92 \mathrm{~mm}$ (diameter of bore at the muzzle in Fig. 7), the liner thickness was calculated to be $1.19 \mathrm{~mm}(0.047 \mathrm{inch})$ at the groove location. This is the thinnest part of the liner. The analogous calculation at the land location gave $1.28 \mathrm{~mm}$ (0.050 inch). The average velocity for the 100 shots was $2,646 \mathrm{ft} / \mathrm{s}$.

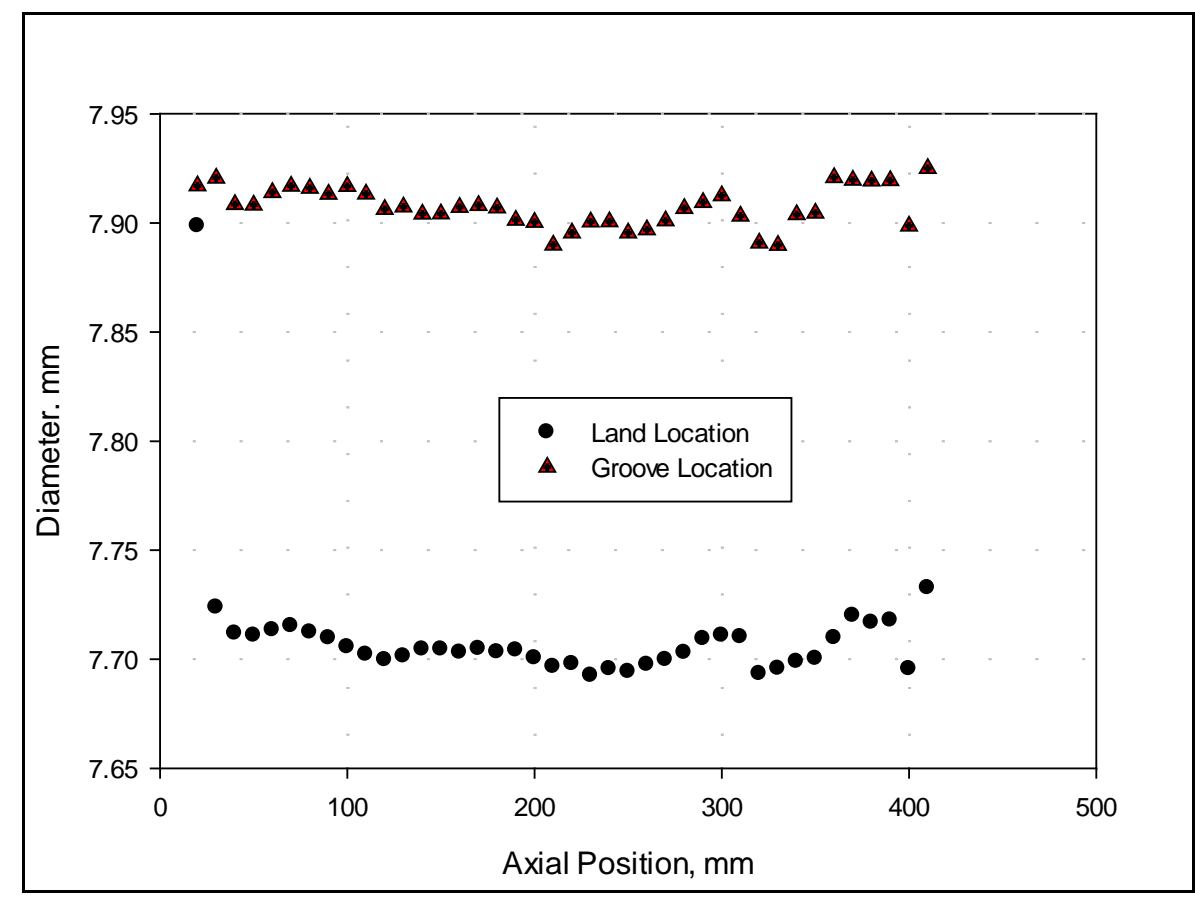

Fig. 7 Bore diameter measurements at the land and groove locations for barrel 1

\subsection{Barrel 2}

The manufacturing of barrels 2 and 3 was dictated by the production schedule of FN. Since they had orders to produce only the short version of the M240, both barrels 2 and 3 were provided to the ARL in this configuration. Even though this was consistent with the first barrel length, the ability to make a standard length, niobium-lined M240 barrel was not demonstrated in this part of the program.

One of the difficulties in the final machining process for lined barrels is machining the chamber area. Here, the machinist must cut through 2 different materials (the gun steel and the niobium liner). A large chunk of the niobium liner in barrel 2 was torn away from the end of the liner at the breech end of the gun tube. FN thought that the tube was not salvageable and sent it back to the ARL. Examination of the tube showed that most of the liner remained in the tube, and it was deemed being capable of firing in the single-shot mode. The tube was sent back to FN for final machining. This delayed the tests with barrel 2. 
The proof slug that FN fired through barrel 2 caused the case to expand into the volume vacated by the torn niobium liner segment. A rod and hammer were needed to push the spent case out of the chamber. There was no protrusion of the liner from the gun barrel noted when the finished barrel was received at ARL.

Firing tests in the Aerodynamics Experimental Test Facility were planned with the expectation that there would be problems in extracting the cartridge case from the chamber. After one shot, the cartridge was extracted in the usual manner. However, the extreme amount of expansion of the cartridge case was observed as it was with the proof slug. The test director halted the tests due to safety and equipment damage issues. No liner movement was observed for the one shot.

\subsection{Barrel 3}

Before firing tests were conducted on barrel 3, its bore diameter was measured with a BEMIS. These measurements are shown in Fig. 8. There was some uncertainty in the measurements near the breech end of the gun tube. The measurements were checked with a similar instrument located at the Aberdeen Test Center. The remeasurements agreed with the ARL measurements except for the high bore diameter points near the breech. The bore diameter of barrel 3 was very close to that of barrel 1 . The bore diameter for both barrels at the groove location was approximately $7.70 \mathrm{~mm}$. This is $0.08 \mathrm{~mm}$ (0.003 inch) larger than the nominal bore diameter for the standard $7.62 \mathrm{~mm}$ weapon. FN (email from Bob Sewell, FN, August 2014, unreferenced) confirmed that the mandrel used in the hammer forging process for unplated barrels was used to make the lined barrels.

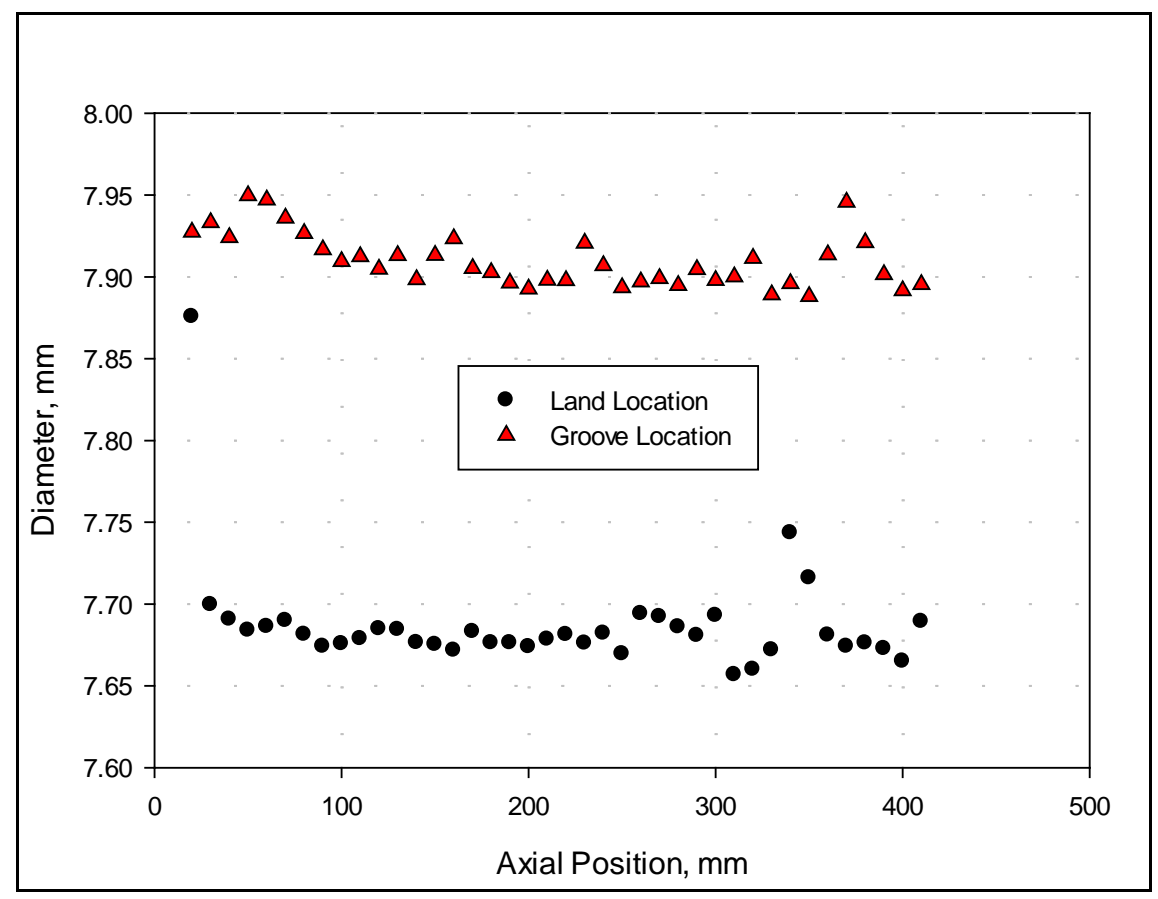

Fig. 8 Bore diameter measurements at the land and groove locations for barrel 3 
The dispersion values are shown in Table 5. These values are consistent with those found in barrel 1.

Table 5 Barrel 3 dispersion

\begin{tabular}{|c|c|c|}
\hline \multirow{2}{*}{ Group No. } & \multicolumn{2}{|c|}{$\begin{array}{c}\text { Dispersion } \\
\text { (mils) }\end{array}$} \\
\cline { 2 - 3 } & $\mathbf{X}$ & $\mathbf{Y}$ \\
\hline 1 & 0.395 & 0.498 \\
\hline 2 & 0.527 & 0.547 \\
\hline 3 & 0.426 & 0.509 \\
\hline
\end{tabular}

Special attention was paid to the position of the liner in the tube. A small burr was removed from the end of the niobium liner that made the end of the liner flush with the end of the barrel. Liner extension was monitored throughout the tests, and no movement was detected for the 100 shots fired through the tube. The average velocity for the 100 shots was 2,654 ft/s.

\section{Discussion}

Other than the slight protrusion of the liner in barrel 1, no liner extension was observed as a result of the firing tests of the 3 barrels with niobium liners. The cause of the protrusion cannot be determined at this time. The number of successful test firings without liner movement or stretching indicates that the combination of GLEEM processing and hammer forging provides a bond between the niobium liner and steel gun tube that is sufficient to keep the liner in place during slow-rate firing. Yet to be determined is whether this fabrication process will be successful at higher rates of fire where heating effects may result in decreased bond strength. Also to be determined is whether this approach can be applied to other refractory metals. In particular, cobalt-chromium alloys offer a great deal of potential as liner materials. ${ }^{12,19}$ Nevertheless, the current results represents a major milestone in the development of refractory metal liners for small arms.

The change in liner diameter as a result of the hammer forge process indicates that a great deal of plastic deformation has occurred in the liner. The outer diameter of the liner started at $10.97 \mathrm{~mm}$ (0.432 inch) and ended up at $10.30 \mathrm{~mm}$ (0.4055 inch). That is, the liner thickness decreased from 1.524 to $1.19 \mathrm{~mm}$ ( 0.060 to $0.047 \mathrm{inch})$ at the groove location. The outer diameter of the steel barrel blank started at 11.337 inches (33.96 $\mathrm{mm}$ ); the outer diameter for the finished barrel was 1.085 inches $(27.56 \mathrm{~mm})$ over much of its length. The hammer forge process, in effect, extrudes both the liner and gun barrel together at the same time. This may result in the creation of fresh, oxide-free surfaces in close contact that are welded together, forming a stronger bond than that achieved solely by the GLEEM process. 
Original test plans called for the measurement of the bond strength of the liner to the steel. However, the final liner thickness was too small for this measurement to be made with the standard test fixture. ${ }^{9,10}$ Not enough data points were generated to be able to say definitively that the liner with the cold-sprayed tungsten-carbide particles provided a greater bond strength than the liners without the coating. It is likely that the added bond strength due to the hammer forging process overwhelms any difference in bond strength produced by the particles.

As noted in Section 4.3, the final liner inner diameter was $0.008 \mathrm{~mm}$ (0.003 inch) larger than the standard production model. This may have been caused by the thinning of the liner over the amount that might have been expected if the niobium were replaced with steel. The average muzzle velocities of the 2 lined barrels were close to 2,650 ft/s. There is no specification for the muzzle velocity for the short-barrel version of the M240 machine gun. However, the muzzle velocity of the standard production model of the short-barrel M240 is close to 2,740 ft/s (email from Robert Sewell, FN Manufacturing, August 2014, unreferenced). The larger bore diameter of the niobium-lined barrels may have allowed some blow-by of the propellant gases, thus decreasing the muzzle velocity to some extent. In any event, some adjustments in the mandrel dimension and the initial liner thickness would have to be made in the production process to achieve the desired final bore diameter.

The dispersion requirement for the standard M240 machine gun is that after 3 warmer shots, the distance between any 2 target hit locations is less than $30 \mathrm{~cm}$ in a 10-round shot group (email from Robert Sewell, FN Manufacturing, August 2014, unreferenced). Examination of the targets produced in these tests showed that this criterion was met in all cases.

Limited firing tests (100 shots or less) were conducted on all 3 barrels. The main purpose of the tests was to see if the liner moved or stretched. No liner extension was observed for the first barrel in the last 60 shots of the series. No liner extension was seen for the third barrel for the 100 shots. Only one shot was carried out with the second barrel due to safety and equipment damage concerns.

\section{Conclusions}

The single-shot tests conducted with the M240 machine gun barrels lined with niobium have demonstrated that the process used to fabricate these barrels is satisfactory. The barrels tested showed acceptable accuracy, and no catastrophic failures occurred. Further tests are needed to show that the liner stays in place during high rates of fire. 


\section{Summary}

Three M240 machine gun barrels have been fabricated with niobium liners. This was done with a combination of the GLEEM process and hammer forging. For the first barrel, a trial-and error process was used to establish the parameters needed for the GLEEM process. The next 2 barrels used those parameters to attach the niobium liners. The liner used in the third barrel had a coating of tungsten-carbide particles cold spray on it to increase the frictional bond between the liner and gun steel. The barrels with liners were hammer forged by FN.

FN experienced some difficulties in the final machining process of the barrels. The mandrel used to hammer forge the first barrel broke, but FN managed to salvage a usable, short barrel. During the final machining process, a portion of the niobium liner was torn out of the second barrel at the breech end of the tube. The third barrel was made without incident. 


\section{References and Notes}

1. Pepi M, Snoha DJ, Montgomery JS, de Rosset WS. Explosively bonded refractory metal gun tube liners. Aberdeen Proving Ground (MD): Army Research Laboratory (US);

2003 Feb. Report No.: ARL-MR-550.

2. de Rosset WS. Explosive bonding of stellite 25. Aberdeen Proving Ground (MD): Army Research Laboratory (US); 2006 Jun. Report No.: ARL-TR-3816.

3. de Rosset WS. Analysis of explosive bonding parameters materials and manufacturing processes. 2006;21(6):634-638.

4. de Rosset WS, Snoha DJ, Minnicino MA. Strength of an explosively-formed bond. Aberdeen Proving Ground (MD): Army Research Laboratory (US); 2006 Sep.

Report No.: ARL-TR-3889. Also available at http://www.arl.army.mil/www/default.cfm?technical_report=1256 .

5. Miller MD, Audino MJ, Smith SB, Welty AM, Snoha DJ, Gray DM, de Rosset WS. Laboratory investigations of explosively-bonded gun tube liners. Watervliet Arsenal (NY): Benét Laboratories (US); Sep 2009. Report No.: RDAR-WSB-TR-09016.

6. Miller MD, Campo F, de Rosset WS. Explosive bonding of refractory metal liners. Poster presented at: 27th Annual Army Science Conference. Proceedings of the 27th Annual Army Science Conference; 2010 Nov 29-Dec 2; Orlando, FL.

7. Carter RH, de Rosset WS, Gray DM. GLEEM - A new composite gun tube processing technology. Poster presented at: 26th Annual Army Science Conference. Proceedings of the 26th Annual Army Science Conference; 2008 Dec 1-4; Orlando, FL.

8. de Rosset WS. Gun liner emplacement with an elastomeric material. Aberdeen Proving Ground (MD): Army Research Laboratory (US); 2010 Apr. Report No.: ARL-CR-645. Also available at http://www.arl.army.mil/www/default.cfm?technical_report=1996 .

9. de Rosset WS. Gun liner bond strength studies. Aberdeen Proving Ground (MD): Army Research Laboratory (US); 2010 June. Report No.: ARL-CR-649. Also available at http://www.arl.army.mil/www/default.cfm?technical_report=1991.

10. de Rosset WS. Gun liner bond strength studies. Materials and Manufacturing_Processes. 2012;27(8):811-814. 
11. de Rosset WS, Gray DM. Refractory metal liner processing for M242 medium caliber barrels. Aberdeen Proving Ground (MD): Army Research Laboratory (US); 2013 Jan. Report No.: ARL-TR-6301. Also available at http://www.arl.army.mil/www/default.cfm?technical_report=6642

12. Montgomery JS, Garner J, Keppinger R, Eichhorst C, de Rosset WS. Tests of M249 barrels made with a cobalt-chromium alloy. Aberdeen Proving Ground (MD): Army Research Laboratory (US); 2011 Dec. Report No.: ARL-TR-5851.

13. de Rosset WS, Montgomery JS. Advanced materials gun tube wear. Aberdeen Proving Ground (MD): Army Research Laboratory (US); 2012 Apr. Report No.: ARL-TR-5986.

14. Witherell M. Calculation of thermal effects in medium caliber gun tubes. Watervliet Arsenal (NY): Benét Laboratories (US); Report No.: ARWSB-TR-10009.

15. de Rosset WS, Montgomery JS. Machine gun liner bond strength. Aberdeen Proving Ground (MD): Army Research Laboratory (US); 2007 Aug. Report No.: ARL-CR-595. Also available at http://www.arl.army.mil/www/default.cfm?technical_report=1455 .

16. MatWeb: material property data. New York (NY): MatWeb LLC; c1995 [accessed 2013 Apr 13]. http:www.//matweb.com/.

17. BEMIS is a registered trademark of Laser Techniques, Inc., of Redmond, WA.

18. Vascomax 300 is a registered trademark of ATI Allvac, Pittsburgh, PA.

19. Leto VE, Klimm BD, Hespos MR, Garron RF. Flowformed cobalt alloy barrel testing on the M240 machine gun. Picatinny Arsenal (NJ): ARDEC technical report to be published. 


$\begin{array}{cl}1 & \text { DEFENSE TECHNICAL } \\ \text { (PDF) } & \text { INFORMATION CTR } \\ & \text { DTIC OCA } \\ 2 & \text { DIRECTOR } \\ (\mathrm{PDF}) & \text { US ARMY RESEARCH LAB } \\ & \text { RDRL CIO LL } \\ & \text { IMAL HRA MAIL \& RECORDS MGMT } \\ 1 & \text { GOVT PRINTG OFC } \\ (\mathrm{PDF}) & \text { A MALHOTRA } \\ 2 & \text { DIR USARL } \\ (\mathrm{PDF}) & \text { RDRL WMM F } \\ & \text { W DE ROSSET } \\ & \text { RDRL WMM B } \\ & \text { D GRAY }\end{array}$

